\title{
Florestan Fernandes e o dilema educacional brasileiro
}

Marcos Marques de Oliveira ${ }^{1}$

\section{Resumo}

Há na sociologia de Florestan Fernandes (1920-1995), em seu projeto para o Brasil, uma preocupação premente com a questão educacional, um dos vetores de modernização das relações sociais, considerado por ele como o principal mecanismo de difusão de uma consciência científica da sociedade e, por isso, um importante instrumento de mudança social. Esta é a hipótese que atravessa este artigo, que identifica as reflexões sobre o dilema educacional brasileiro na obra de Florestan, com ênfase na investigação de sua participação num dos debates mais relevantes da História da Educação brasileira, quando foi aberta a oportunidade de se organizar o sistema nacional de ensino através dos preparativos para a nossa primeira Lei de Diretrizes e Bases (LDB), entre os anos de 1948 e 1961.

Palavras chaves: Florestan Fernandes; Sociologia; Educação Brasileira; Revolução Burguesa.

\begin{abstract}
In Florestan Fernandes's sociology (1920-1995), in his project for Brazil, there is a pressing concern with the educational issue, one of the vectors of modernization of social relations, considered by him as the main mechanism of diffusion of a scientific awareness of therefore an important instrument of social change. This is the hypothesis that crosses this text, which identifies the reflections on the Brazilian educational dilemma in Florestan's work, with emphasis on the investigation of his participation in one of the most relevant debates in the History of Brazilian Education, when the opportunity was opened to organize the national education system through preparations for our first Guidelines and Bases Act (LDB) between 1948 and 1961.
\end{abstract}

Keywords: Florestan Fernandes; Sociology; Brazilian Education; Bourgeois Revolution.

\footnotetext{
${ }^{1}$ Pós-doutorando do Programa de Pós-Graduação em Sociologia Política da Universidade Estadual do Norte Fluminense Darcy Ribeiro (UENF). Professor de Sociologia do Programa de Pós-Graduação em Educação da Universidade Federal Fluminense (UFF).E-mail: <marcos_marques@id.uff.br>
} 


\section{Introdução}

Há na sociologia de Florestan Fernandes (1920-1995), em seu projeto para o Brasil, uma preocupação evidente com a questão educacional, um dos vetores de modernização das relações sociais, considerado por ele como o maior instrumento de difusão de uma consciência científica da sociedade e um importante mecanismo de mudança social - que tem como base, entre outros fatores, a relação entre educadores e educandos. Esta é a hipótese que perseguiremos neste texto, identificando as reflexões sobre o dilema educacional brasileiro na obra de Florestan, investigando especialmente sua participação num dos debates mais relevantes da História da Educação brasileira, quando foi aberta a oportunidade de se organizar o sistema nacional de ensino através da primeira Lei de Diretrizes e Bases (LDB), entre os anos de 1948 e 1961.

Neste terreno de combate, Florestan vai defender, através de comícios, palestras e artigos, a democratização do ensino e combater o uso da educação como mecanismo de privilégio social. O ponto fundamental para a efetiva adequação da educação às necessidades sociais de transformação social progressiva em uma determinada sociedade, irá defender o sociólogo, dependerá “da intensidade, do volume e da direção das esperanças coletivas" (FERNANDES, 1971, p.198) que o conjunto da população depositará, justamente, na educação sistemática. Articulado a este processo, estará o papel do professor como agente promotor de mudança social. No seu caso particular, vale ressaltar, como já defendido em outro texto, este papel se mostrará maduro quando, fora da universidade, advogará para si a missão de esboçar uma concepção educacional "revolucionária” capaz de, potencialmente, colaborar na transformação da sociedade brasileira (OLIVEIRA, 2010).

Para o que interessa aqui, acreditamos que acompanhando esta sua transição de militante da ciência para o professor da política, analisando as lutas travadas por ele no campo do ensino para ocupar os vazios deixados pela interrompida "revolução burguesa" (FERNANDES, 1975), poderemos encontrar insumos para compreender e, se for o caso, combater o "universo mental" conservador-reacionário que hoje parece estar satisfeito com os limites de uma "cidadania restrita" e de uma "democracia como estilo". Padrão cultural que, caso permaneça hegemônico, tenderá a contribuir para perpetuar as desigualdades sociais, as condições indignas de vida e a ignorância pública. Efeitos diretos da falta de 
oportunidades educacionais e do incremento da apropriação privada do conhecimento produzido socialmente.

\section{O dilema educacional brasileiro}

Poucos países, no mundo moderno, possuem problemas educacionais tão graves, quanto o Brasil. Como herança do antigo sistema escravocrata e senhorial, recebemos uma situação dependente inalterável na economia mundial, instituições políticas fundadas na dominação patrimonialista e concepções de liderança que convertiam a educação sistemática em símbolo social dos privilégios e do poder dos membros e das camadas dominantes. O fardo era pesado demais, para ser conduzido, com responsabilidade e espírito público construtivo, num sistema republicano que se transformou, rapidamente, numa transação com o velho regime, do qual se tornou mero sucedâneo político (FERNANDES, 1971, p. 192).

Com essas palavras², o sociólogo Florestan Fernandes apresentava, no final dos anos 1950, sua apreciação sobre o "dilema educacional brasileiro", pelo qual observava o desajuste qualitativo e quantitativo de nosso sistema de ensino frente às necessidades da nação e de suas regiões. A estabilidade e a evolução do regime democrático estariam exigindo a extensão das influências socializadoras da escola às camadas populares, assim como a transformação rápida do estilo de trabalho didático tradicional, que não era propício à formação de personalidades democráticas. Na medida em que o sistema educacional restringia a procura dos candidatos à escolarização e se tornava inerte em relações às mudanças solicitadas, incluía-se entre os fatores adversos ao desenvolvimento social. "Por conseguinte, em vez de acelerar a difusão e o fortalecimento dos ideais de vida, consagrados legalmente, ele interfere no processo como fator de demora cultural" (FERNANDES, 1971, p. 197).

O tal "dilema" funciona como um círculo vicioso no qual as condições de subdesenvolvimento geram problemas cuja gravidade aumenta em função das dificuldades materiais ou humanas em resolvê-los. A intervenção conjuntural deliberada, ainda que topicamente bem-sucedida, acaba por contribuir pouco para alterar a situação estrutural. O esforço, por isso, precisa ser repetido diversas vezes para que não se perca a pequena vantagem conquistada.

\footnotetext{
2 Que fazem parte de "A ciência aplicada e a educação como fatores de mudança cultural provocada", texto escrito para o Simpósio sobre os Problemas Educacionais Brasileiros, organizado pelo Centro Regional de Pesquisas Educacionais de São Paulo, no ano de 1958 (FERNANDES, 1971).
} 
Pensamos que este esboço remata a caracterização do que chamamos de "dilema educacional brasileiro". A relação entre meios e fins, no que concerne às perspectivas de controle dos problemas educacionais mais prementes, não prenuncia nenhuma espécie de êxito seguro e rápido. Tal circunstância indica, de ângulo inteiramente positivo, que a transformação do sistema educacional de um povo em fator de desenvolvimento depende, de modo direto, da intensidade, do volume e da direção das esperanças coletivas, depositadas na educação sistemática (FERNANDES, 1971, p. 198).

A esperança coletiva na universalização qualitativa da educação escolar sistemática, portanto, deveria persistir para a transformação da ordem. Isso porque, segundo Florestan, "não há dúvida de que a educação modela o homem. Mas é este que determina, socialmente, a extensão das funções construtivas da educação em sua vida" (FERNANDES, 1966, p. 71). Mantendo a esperança nas possibilidades das mudanças sociais planejadas, Florestan advoga pela associação entre educadores e cientistas sociais para a elaboração de projetos que contribuam para a descoberta de meios adequados, econômicos e rápidos para uma intervenção racional na estrutura e no funcionamento do ensino brasileiro.

Ainda que envolva ônus financeiros severos para um país pobre e destituído, inclusive, de uma rede escolar para atender as emergências, a respectiva associação abre perspectivas encorajadoras, "por permitir articular a solução dos problemas educacionais ao conhecimento e ao controle efetivo dos fatores responsáveis pelo estado de pauperismo, de subdesenvolvimento e de desequilíbrio institucional da sociedade brasileira" (FERNANDES, 1971, p. 193).

No entanto, alguns aspectos precisam ser considerados. O primeiro é o cuidado em combater a noção de que o cientista social tem condições de "resolver", por si, os "problemas educacionais". Para Florestan, semelhante perspectiva não tem fundamento já que "os problemas educacionais brasileiros só poderão ser resolvidos através da mudança social organizada" (FERNANDES, 1971, p. 193), dependendo ainda da forma como o cientista social for incluído no processo e das potencialidades de mudança do meio social ambiente. O segundo, em decorrência do anterior, é que para o sucesso da associação entre cientistas e educadores, a comunicação social aparece como um terceiro vértice do triângulo:

A imprensa, a divulgação da leitura e outros meios modernizados de comunicação têm tornado o conhecimento de senso comum mais acessível à contribuição dos educadores e, mesmo, dos cientistas sociais. Vice-versa, estes vêm demonstrando maior interesse pelas manifestações 
dos leigos, chegando a estimular movimentos que os convertem em grupos de pressão na área de reconstrução educacional (FERNANDES, 1966, p. 104).

Isto porque, afirma o sociólogo, qualquer conhecimento positivo produzido sobre a situação educacional brasileira será impotente, por si mesmo, para alterar a qualidade e a eficácia da reação societária aos problemas educacionais. "Essa circunstância só se alterará, presumivelmente, na medida em que se puder combinar, produtivamente, esse conhecimento com a atividade regular dos educadores militantes e com o conhecimento do senso comum escolarizado" (FERNANDES, 1966, p. 110). Ao fim, além dos conhecimentos sobre a situação e os alvos a serem alcançados, os especialistas devem dispor de boas condições de trabalho para que possam regular, institucionalmente, sua participação na elaboração, na aplicação e no controle dos planos de intervenção esboçados. Daí, afirmará Florestan, a importância da existência de organizações como o Centro Brasileiro de Pesquisas Educacionais (CBPE), que regiam os Centros Regionais de Pesquisas Educacionais (CRPE) em alguns estados da federação:

Ele [o CBPE] introduz o planejamento, como processo social, na esfera da educação sistemática no Brasil e confere ao sociólogo, dentro dele, papéis sociais que lhe permitem colaborar, regularmente, nas fases de elaboração e de aplicação de planos de controle educacional em que se imponha a utilização de conhecimentos sociológicos (FERNANDES, 1971, p. 194).

Percebe-se, assim, como Florestan estava vinculado ao movimento de fomentação e consolidação das pesquisas educacionais no Brasil, que tem entre seus maiores representantes Anísio Teixeira e Fernando de Azevedo, respectivamente, diretores do CBPE e do CRPE de São Paulo, organizações criadas com a pretensão de fazer com que as atividades educacionais alcançassem "condições científicas" através da colaboração das ciências sociais.

Pesquisa no Brasil lembra sempre coisas feitas um pouco no ar. Um prédio de cerca de 200 metros de longo e 20 de largo para pesquisas parece um absurdo. E pesquisas de educação? Ainda mais. É que não pensam que o setor de documentação, o de programas, o de psicologia, o de testes e medidas, o de administração, o de livros e material do ensino são imensos departamentos, que o meu Centro, apesar de grande, acabará por não comportar. Medicina é, sem dúvida, um imenso campo de pesquisas. Pois bem: o de educação não é, mas devia ser bem maior (TEIXEIRA apud FERREIRA, 2001, p. 11). 


\section{A nossa primeira LDB}

Vale lembrar que essas reflexões são feitas num momento marcante na história educacional do país, quando se abre oportunidade de organizar o sistema de ensino nos debates para a configuração da primeira Lei de Diretrizes e Bases da Educação Nacional (LDB). Segundo Florestan, o lado construtivo deste clima propício à mudança cultural provocada ${ }^{3}$ foi o fato dele ter sido imaginado, pelos educadores brasileiros, como um expediente para modificar a orientação de manutenção e extensão das oportunidades educacionais como mecanismo de privilégio às camadas mais bem-sucedidas na competição econômica, social e política.

Surgiu, desta forma, como a primeira grande chance que tivemos de submeter uma grande área de nossa estrutura escolar a uma disciplina nova, "mais coerente com as necessidades educacionais fomentadas pela formação e desenvolvimento da sociedade de classes, do regime democrático e da civilização tecnológica-industrial no Brasil”" (FERNANDES, 1966, p. 130). A seu ver, “jamais se vira semelhante movimento de opinião em torno dos problemas educacionais brasileiros" (FERNANDES, 1966, p. 355) desde o Manifesto dos Pioneiros da Educação Nova, de 1932, que tinha como objetivo nortear a criação de um sistema de educação de caráter orgânico e integrado, capaz de submeter as tendências de diferenciação e descentralização a um conjunto comuns de fins e princípios diretores básicos.

A principal contribuição do Manifesto foi ter influenciado a Constituição de 1934, especialmente os artigos 05 e 150, que estabelecia como competência da União traçar as diretrizes educacionais, assim como a fixação de um plano nacional que compreendesse todos os níveis de ensino, com a responsabilidade de coordenar e fiscalizar sua execução. Após o período ditatorial do Estado Novo, no qual este debate ganha outro rumo ${ }^{4}$, a

\footnotetext{
${ }^{3}$ Florestan ressalta que "a diferença entre a mudança cultural espontânea e a mudança cultural provocada (quanto ao papel do elemento racional, encarado nos limites da civilização tecnológica e industrial), é antes de grau, que de natureza. [...] Distinguem-se uma da outra somente com referência aos recursos técnicos e intelectuais, postos à disposição do homem no campo do comportamento inteligente e do controle deliberado de 'forças' conhecidas no meio ambiente" (FERNANDES, 1971, p. 190).

${ }^{4}$ De acordo com Xavier (1990, p. 82), “as reformas educacionais empreendidas nas décadas de 30 e 40 visavam, a um só tempo, a responder às exigências político-ideológicas do momento e às pressões sociais traduzidas e reforçadas pelo
} 
Constituição de 1946 manteve essa determinação, dispondo que competia à União legislar sobre ela. No ano seguinte, a pedido de Clemente Mariani, então ministro da Educação, uma comissão foi constituída para preparar um esboço do projeto de lei, que foi encaminhado ao Congresso Nacional em outubro de 1948.

Os trezes anos decorridos entre 1948 e 1961 são uma etapa particularmente ideologizada do conflito público-privado na área educacional. O período iniciou-se com o já citado projeto de lei de Clemente Mariani, que conjugava, segundo Xavier (1990, p. 120), os arroubos típicos da "retórica progressista nacional", além de um diagnóstico surpreendentemente correto do resultado das reformas anteriores, com a denúncia do tradicional dualismo da educação brasileira, que havia sido aprofundado pelo regime autoritário e cuja correção deveria ser efetuada pelo governo democrático.

Entretanto, o projeto não passou de um conjunto de propostas moderadas para a solução de diversos problemas da educação brasileira, tais como: o conflito centralização versus descentralização (através da busca de harmonia entre as funções dos estados e da União, pela unidade nos objetivos e variedade nos métodos); e, para a articulação dos vários ramos de ensino (através de uma nova reforma do ensino médio com a superação de barreiras entre o estudo acadêmico e o técnico). Além disso, apesar de indicar o dever do Estado na garantia de educação para todos, partindo do pressuposto da "escola equalizadora", o projeto original admitia incentivos para o ensino privado e induzia a uma concepção supletiva da ação estatal, reforçando o seu caráter moralizador e fiscalizador. De novidade, somente a referência às novas elites, a flexibilidade que se abria a outros grupos sociais de acesso ao ensino superior, através da equivalência entre os ramos técnicos e o secundário.

Desta forma, as pretensões democráticas do projeto Mariani assumem as dimensões reais compatíveis com a realidade econômica e política subjacente, mantendo a formação dual e discriminatória.

Não se eliminava, assim, a barreira educacional entre as classes sociais, mas ampliava-se a oferta de oportunidades educacionais para uma classe média em rápida expansão, foco central das pressões sociais e das políticas "democratizadoras", na sociedade brasileira em transição (XAVIER, 1990, p. 126).

novo ideário". No caso específico do Estado Novo, o ideário escola-novista entra em recesso, ganhando força as propostas de centralização autoritária de Gustavo Capanema (SCHWARTZMAN; BOMENY; COSTA, 1984). 
O motivo para rejeição e arquivamento do projeto Mariani não foi, como registram alguns estudos 5 , o seu caráter "democrático" e "progressista", mas sim, uma questão de ordem política, relativa a interpretações específicas sobre a questão da centralizaçãodescentralização. Em seu parecer à Comissão Mista de Leis Complementares do Congresso Nacional, o deputado Gustavo Capanema, ministro da Educação durante o Estado Novo, destaca a inconstitucionalidade do projeto pela sua extremada concepção de descentralização. Na opinião de Capanema, que reconhece o esmero científico e técnico e a elevação de propósitos culturais contido no documento, o projeto pecava pela atribuição aos estabelecimentos de um desmedido arbítrio para organização de seus conteúdos de ensino e pela ampla competência que dava aos estados e municípios na organização dos diversos ramos de ensino. Entretanto, segundo Xavier (1990), as interpretações conflitantes se orientavam pela ambiguidade, quiçá estratégica, das determinações legais.

O projeto foi arquivado e ficou sem andamento até julho de 1951, quando a Comissão de Educação e Cultura da Câmara solicita ao Senado o seu desarquivamento. A resposta de extravio fez com que a mesa da Câmara determinasse sua reconstituição, o que aconteceu a partir da criação de várias subcomissões, da anexação de um projeto da Associação Brasileira de Educação (ABE) e da consulta a vários educadores. Em 1955, 14 processos já tinham se somado ao projeto, incluindo um primeiro substitutivo apresentado pelo deputado Carlos Lacerda, cujo texto estava próximo do projeto original. Em 1956, após o parecer favorável de mais uma comissão, o projeto voltou a ser debatido no Legislativo.

O primeiro discurso de grande impacto foi o do padre Fonseca e Silva, no dia 5 de novembro, cujo mérito foi "obrigar os interesses conflitantes a se manifestarem num jogo político aberto" (BUFFA, 1979, p. 21). Em sua fala, o deputado adverte o então ministro da Educação contra a presença de Anísio Teixeira e Almeida Jr., respectivamente, na direção do então Instituto Nacional de Estudos Pedagógicos (INEP) e na presidência do I Congresso Estadual de Educação, em São Paulo. Alega para tanto, que tais professores não

\footnotetext{
${ }^{5}$ Conferir, por exemplo, Romanelli (1999, p. 174).
} 
passam de "agnósticos" e "comunistas", que ocupavam altos postos para liderar uma campanha contra a "formação religiosa" do povo brasileiro'.

No dia 10, Fonseca e Silva envia um memorial ao ministério, reforçando as críticas e alertando para as restrições sofridas pelo patrimônio moral e espiritual da Igreja, denunciando que estaria sendo desenvolvido um movimento contra o ensino particular brasileiro. Em fins de novembro, o deputado Luís Vianna responde às acusações, dando a conhecer à Câmara dois documentos: um do ministro Clóvis Salgado e outro do próprio Anísio Teixeira, todos refutando as idéias contidas no discurso de Fonseca e Silva, principalmente no que se referia aos vínculos com a ideologia marxista ${ }^{7}$. Posteriormente, a polêmica sai do Congresso, atravessa círculos intelectuais e chega à opinião pública, envolvendo disputas através da imprensa e manifestações de diversos tipos.

Só em 1957, em parte sob a pressão dos educadores e o clamor da opinião pública esclarecida e em parte sob a exigência de circunstâncias imperiosas, o assunto passou a tramitar com maior rapidez pela Comissão de Educação e Cultura. No entanto, as forças que se opunham ao feitio laicista-liberal do projeto primitivo, responsáveis pela estagnação do processo, conseguiram imprimir novos rumos à discussão e à votação da matéria (FERNANDES, 1966, p. 425).

Em meio à disputa, segue a tramitação do projeto. Em 29 de maio de 1958, a Comissão de Educação e Cultura aprova um novo substitutivo, que em segunda discussão, em novembro do mesmo ano, recebe três emendas, o que o faz retornar à Comissão. Em dezembro de 1958, Carlos Lacerda, "amigo da livre iniciativa” (FERREIRA e OLIVEIRA, 1997, p. 34), apresenta mais um substitutivo, não colocado em debate. Em janeiro de 1959, o deputado apresenta um terceiro substitutivo, dando uma reviravolta na direção das discussões, fazendo com que a questão educacional assumisse definitivamente um novo caráter ideológico, com a polêmica "descentralização versus centralização" sendo substituída definitivamente pelo conflito "escola pública versus escola privada" (ROMANELLI, 1999). De acordo com Florestan, o “substitutivo Lacerda” era estratégico:

\footnotetext{
${ }^{6}$ Designados como “agitadores comunistas" também serão os universitários que lutavam por sua representação nos órgãos de administração e direção das universidades brasileiras, como lembra Florestan no artigo "A representação dos alunos", publicado pela revista Anhembi, em setembro de 1962 (FERNANDES, 1966).

7 Segundo Nunes (2001, p. 9), apesar de simpatia por algumas idéias comunistas, "Anísio nunca abandonou a concepção de educação como uma prática atravessada pela ciência e, ao mesmo tempo, pela arte que relativiza o peso da ciência na educação. É pelo seu amor a ambas que, mesmo tendo escrito um programa partidário no momento em que sua obra estava ameaçada, se afasta dos partidos. Ele recusava a noção de ordem, lealdade, hierarquia e o desprezo pela discussão teórica, comuns nas hostes partidárias de então". Na base de sua formação, estavam o próprio catolicismo e o pragmatismo de John Dewey.
} 
"levou tão longe o favoritismo à escola privada, que deveria servir, forçosamente, como peça de composição” (FERNANDES, 1966, p. 425).

\section{O embate entre o público e o privado}

Vale ressaltar que o documento apresentado pelo deputado estava calcado nas conclusões do $3^{\circ}$ Congresso Nacional dos Estabelecimentos Privados de Ensino, realizado há mais de dez anos, com a exacerbação de alguns pontos já presentes no projeto Mariani, principalmente no que se referia ao caráter complementar da ação estatal e ao ensejo da cooperação entre a iniciativa privada e o governo. Previa que a admissão gratuita de alunos nas escolas particulares ou a redução da contribuição seria compensada por bolsas e outras vantagens do governo. O "substitutivo Lacerda", como ficou conhecido, no seu Título IV, deixava explícito o caráter supletivo do ensino público pela vedação do favorecimento ao monopólio estatal e pela igualdade de condições entre as escolas oficiais e particulares, no que tocava, inclusive, à distribuição de verbas (através de bolsas, financiamentos para construção ou reforma de prédios, além da compra de equipamentos).

Sob o impacto desse substitutivo, a sociedade se mobiliza e recrudesce-se o embate das "ideologias em conflito", no qual Buffa (1979) identifica dois grandes grupos em confronto: um a favor do ensino privado; outro a favor da escola pública. No primeiro, a autora encontra como principal articuladora a Igreja Católica, que levantou a bandeira da liberdade de ensino como liberdade de escolha do tipo de escola pela família, objetivando, entre outras coisas, a subvenção pública e a não ingerência do Estado. Subordinada a ela, estariam as escolas particulares leigas, que sem uma doutrina própria, apoiavam-se na da Igreja para defender interesses "principalmente financeiros". Ressalta-se, porém, que a participação das escolas leigas, apesar da menor visibilidade, continha um significado político importante por representar a gênese de uma identidade empresarial - a Federação Nacional dos Estabelecimentos de Ensino - que, no futuro, se fortalecerá em torno dos chamados "interesses financeiros" (COSTA, 2004).

Antecipando este argumento, Florestan já apontava, em pleno debate, que os "motivos estritamente pecuniários" era o fulcro de toda mobilização privatista:

As escolas particulares leigas, abrindo mão do princípio de que "a escola particular para ser livre precisa ser economicamente independente", deram 
relevo à maior participação do Estado no financiamento de empresas de ensino lucrativas, por motivos estritamente econômicos. Está claro que a situação educacional brasileira exige que o Estado intervenha segundo novo estilo no crescimento educacional. Se isso acontecer e o sistema público de ensino absorver a capacidade de intervenção do Estado, o caminho para a progressiva diminuição da clientela das escolas particulares estará aberto. Vê-se que não temem, propriamente, a concorrência com as escolas públicas na situação atual. Temem, isto sim, as medidas que poderiam transformar em adversas as vantagens existentes no momento, graças à própria omissão do Estado em suas tarefas educacionais. As escolas particulares católicas, como e enquanto empresas econômicas, são movidas pelos mesmos motivos. Graças a razões espirituais, acrescem a esses motivos a defesa da posição dominante que a Igreja Católica sempre ocupou na formação intelectual e moral do homem na ordem tradicional. Essa posição foi mais ou menos ameaçada pela expansão do sistema público de ensino, o que estimulou os sacerdotes católicos a lutarem aberta e denodadamente por novos meios de revitalização do sistema escolar submetido ao controle direto da Igreja Católica (FERNANDES, 1966, p. 132).

No outro flanco, os defensores escola pública assim se dividiam: os liberais-idealistas, que viam a educação com o objetivo supremo de afirmação da individualidade, em termos universais e eternos; os liberais-pragmáticos, que utilizando argumentos de ordem prática, preconizavam a maior eficiência da escola pública e o seu maior atendimento às necessidades imediatas do país; e os de tendência socialista, que viam no ensino público um instrumento eficaz na superação do "subdesenvolvimento" político, econômico, social e cultural (BUFFA, 1979). Desse grupo, a manifestação de maior impacto foi, sem dúvida, a "Campanha em Defesa da Escola Pública", do qual participaram líderes sindicais, antigos educadores do movimento escolanovista, estudantes e intelectuais universitários - entre eles, Florestan Fernandes ${ }^{8}$, “a liderança mais expressiva e combativa do movimento em defesa da escola pública naquele período”, afirma Saviani (1996, p. 79), baseando-se nas palavras de outro partícipe do movimento, Roque Spencer Maciel de Barros:

Não podemos deixar de registrar o trabalho pertinaz do professor Florestan Fernandes, levando para todos os cantos do nosso estado - e mesmo para outras unidades da Federação - uma palavra de esclarecimento sobre os defeitos e perigos do projeto que a Câmara dos Deputados aprovou em janeiro último, numa autêntica "peregrinação cívica e pedagógica" que é um fato inédito nos anais de nossa história da educação. Dezenas e dezenas de conferências fez o professor Florestan Fernandes, tornando-se credor da admiração e simpatia de todos os que

\footnotetext{
8 De acordo com Romão (2003, p. 40), além de participar da Campanha "com todas as suas forças", Florestan mobilizou para ela alguns de seus assistentes na USP, tais como Fernando Henrique Cardoso, Marialice Foracchi, Octavio Ianni e Luiz Pereira.
} 
lutam pela causa da educação nacional (BARROS apud SAVIANI, 1996, p. 79).

Desse grupo saiu um novo substitutivo que foi levado à Câmara pelo deputado Celso Brant, ainda em 1959 (ROMANELLI, 1999, p. 176). Em linhas gerais, os defensores da escola pública indicavam as seguintes medidas para o ajustamento "da educação aos requisitos econômicos, políticos, sociais e culturais da ordem social vinculada ao regime democrático, à economia mecanizada e à civilização tecnológica-industrial”:

Em primeiro lugar, impõe-se estender o ensino primário a todos os indivíduos em idade escolar (ou acima desta, quanto não o possuam) e assegurar a todas as regiões do País, independentemente de sua estrutura demográfica e de suas riquezas econômicas, meios para incentivar esse desiderato. [...] Em segundo lugar, impõe-se diferenciar internamente o sistema educacional brasileiro, de modo a dar maior amplitude às funções educacionais dos diferentes tipos de escolas, ajustando-as convenientemente às necessidades educacionais das diversas comunidades humanas brasileiras. [...] Da escola primária à escola técnica e à escola superior, democratização do ensino, aqui, significa, literalmente, revolução educacional: leva-nos primordialmente para a mudança de mentalidade e de hábitos pedagógicos, redefinindo o uso social da educação através de novas concepções educacionais e da correspondência efetiva para com as exigências educacionais de nossa época. [...] Em terceiro lugar, por fim, impõe-se abolir a seleção educacional com fundamento em privilégios (de riqueza, de posição social, de poder, de raça ou de religião) (FERNANDES, 1966, p. 128-129).

A seguir, a Comissão de Educação e Cultura da Câmara nomeia uma subcomissão para examinar os dois substitutivos (o de Lacerda e o da Campanha), as emendas apresentadas pelos deputados e elaborar um último anteprojeto; aprovado em janeiro de 1960. Nos meses posteriores, continuam as discussões na imprensa. Alguns membros da Campanha, entre eles Florestan, chegam a formar uma comissão para ir a Congresso e pressionar contra o documento aprovado. No relatório sobre a respectiva visita, para a efetiva rejeição do texto aprovado, a comissão alerta para a necessidade de mudança de estratégia, já que - frente aos recursos financeiros e a influência do setor privado - só uma maior mobilização popular poderia obter êxito para romper o "isolamento" do legislador brasileiro, o que para tanto seria fundamental a preparação de novos documentos, de caráter mais técnico, e a propagação de novos núcleos em defesa da escola pública e da educação popular.

A nossa campanha tem se concentrado no debate das deficiências orgânicas e profundas da lei, insistindo principalmente nas lacunas 
pedagógicas e estruturais do projeto de lei. Essa orientação está certa, situando-nos no plano do debate construtivo dos problemas. Mas, é preciso complementar esse esforço de esclarecimento, alargando mais as bases e os influxos populares do movimento de defesa da escola pública. Se os estudantes, os professores, os trabalhadores, os intelectuais e os chefes de família em geral não exprimirem de modo mais organizado e viril suas reivindicações contra o projeto de lei, dificilmente os senadores participarão do diálogo com ânimo de nos atender. Em outras palavras, sem imitar as forças que se opõem à revisão do projeto de lei e reproduzir seus métodos de luta, devemos incrementar o poder de persuasão da nossa campanha e aumentar a importância das manifestações puramente leigas contra aquele calamitoso esbulho da educação popular (FERNANDES, 1966, p. 520).

No entanto, os resultados do processo acabam por convencer Florestan de que "os chamados 'controles indiretos' só produzem efeitos positivos onde os mecanismos da democracia funcionam com um mínimo de eficácia” (FERNANDES, 1966, p. 508-509).

Cometeu-se um crime contra o ensino, atendendo-se às pretensões das correntes privatistas e às pressões reacionárias de círculos católicos obscurantistas. A verdade insofismável é que o Congresso parece ser cativo dessas forças, não tendo, por isso, meios de consolidar a democracia na esfera do ensino. Acomoda-se, quando devia revoltar-se; omite-se ou tergiversa, quando devia decidir e impor soberanamente as soluções mais convenientes à democratização do ensino e à diferenciação qualitativa do sistema educacional brasileiro (FERNANDES, 1966, p. 514).

A única ressalva feita sobre as forças parlamentares da época foi em relação ao Partido Trabalhista Brasileiro (PTB) que, através de seus líderes no Congresso (o deputado Almino Afonso e o senador Camilo Nogueira Gama), se mostrou interessado "na solução dos problemas da educação popular e de democratização do ensino" (FERNANDES, 1966, p.513). Finalmente, em junho de 1961, o último projeto, favorável à iniciativa privada, é aprovado pela Câmara dos Deputados e enviado ao Senado, que o legitima, no dia 3 de agosto, por 33 votos a 11. Em 20 de dezembro daquele ano, sancionado pelo presidente João Goulart, o projeto de Lei de Diretrizes e Bases da Educação Nacional converte-se, finalmente, na Lei n. 4.024 (ROMANELLI, 1999, p. 179). Sobre o "gesto de soberano desprezo" do presidente diante da democracia e da educação popular, Florestan diz-se não surpreso, apesar da carreira política de João Goulart estar apoiada nas mesmas forças que defendiam a escola pública:

No poder, o Sr. João Goulart redefiniu completamente sua linha de ação política. Membro e representante de camadas sociais privilegiadas e conservadoras, não tem nenhum interesse em pôr em prática uma 
autêntica filosofia de atuação política democrática, que o obrigue a valorizar o ensino público e a estender sua influência na dinâmica do regime representativo (FERNANDES, 1966, p. 522).

No mesmo texto, faz uma menção a Oliveira Brito, o então ministro da Educação:

Os que deviam nos resguardar de riscos dessa natureza comprometem-se na empreitada e tornam-se paladinos de uma triste causa, disfarçada atrás de fórmulas altas, como a enunciada pelo senhor ministro da Educação, [...]: "O ensino é um só. Público ou privado, ele se define pela qualidade que oferece". Essa data ficará na história da educação no Brasil como o dia da "transação final", um dia nefasto, em que os homens incumbidos de velar pela coisa pública decidiram pôr a República em leilão, ferindo-a diretamente no próprio cerne vital da vida democrática - o ensino público (FERNANDES, 1966, p. 525).

Com sua participação na Campanha em Defesa da Escola Pública, a opinião pública, nas palavras de Cardoso (1987, p. 24), passa a conhecer um novo Florestan, complementar ao "trabalhador intelectual" que inaugurou um modo novo de fazer sociologia no Brasil:

Antes de falar no seu trabalho intelectual, gostaria de ressaltar um outro aspecto que sempre coexistiu com o aspecto de Florestan universitário: uma espécie de ira sagrada contra a injustiça. Doía nele, como dói até hoje, a desigualdade, doía nele, como dói até hoje, a discriminação contra os negros, doía nele como dói até hoje, a apropriação privada de bens coletivos, como, por exemplo, a educação. E houve um momento em que nós todos esquecemos um pouco nossos aventais e nos lançamos a uma peregrinação por São Paulo para fazer uma campanha - a Campanha em Defesa da Escola Pública. Este outro Florestan também foi um Florestan seminal, também foi um Florestan que marcou, porque mostrou que o acadêmico pode e deve, em certas circunstâncias, lançar-se a posições concretas de luta para melhorar as condições de vida de seu país. [...] Foi uma mobilização intensíssima, uma mobilização que nos levou àquilo que então ainda era raro: o encontro da universidade com os trabalhadores. Andamos por sindicatos sem fim, pregando. Andamos por escolas, andamos pelo interior, pregando, discutindo modificações concretas em uma lei que iria dar as normas fundamentais ao processo educativo no Brasil (CARDOSO, 1987, p. 25).

\section{Do dilema educacional ao dilema social}

Como se pode perceber pelas citações acima, com o objetivo de conscientizar a população brasileira sobre os problemas educacionais, visando ao exercício legítimo da 
pressão política, o "publicista" Florestan defendeu, através de uma série de artigos?, a democratização do ensino como mecanismo de abolição das barreiras que restringem o uso da educação para a manutenção dos privilégios sociais. Florestan faz isso atravessando diversas dimensões da realidade, sintetizando aspectos micro e macrossociológicos, permitindo um entendimento do "campo educacional”" como uma síntese entre a sociedade, o sistema escolar e o plano pedagógico.

Tanto o discurso como a atuação permanente levam-no a se estender sobre outras conseqüências da democracia. Deste modo, ao lado de reforçar o papel da educação como liberadora da ignorância e também da insegurança, da servidão moral e da miséria, Florestan Fernandes não deixa, simultaneamente, de arrolar as críticas ao caráter antidemocrático e sociopático da estrutura do sistema educacional brasileiro, quando examina o divórcio entre o ensino e as condições sociais de existência. [...] Fechando o quadro de referência mais compreensivo para a análise do processo de educação - com especial ênfase na educação escolarizada Florestan Fernandes ressalta o papel do elemento político no raciocínio, nas opções e nas influências dos educadores, consideradas as condições da vida social na moderna sociedade de massas. Tese das mais abrangentes anteriormente mencionadas, formando um só corpo: o Estado democrático, o direito à educação, o impacto negativo do meio social, a ciência e a tecnologia científica, o uso social da inteligência, a libertação do homem da servidão e da miséria (NAGLE, 1987, p. 191).

A vitória privatista no episódio da LDB, na análise de Florestan, ocorreu pela conjugação de duas variáveis conjunturais: pela forte associação da Igreja Católica com o setor empresarial do ensino, com a primeira lutando para recuperar o monopólio da educação e o segundo tentando evitar a competição com o sistema público em crescimento; e pela qualidade do representante dos interesses das escolas particulares, o deputado Lacerda, uma "mente poderosa" com alta "capacidade da ação parlamentar" (FERNANDES, 1991, p. 39). Mas essas variáveis de conjuntura apenas indicavam a complexidade do dilema social brasileiro, que consiste na resistência sociopática das elites brasileiras a qualquer proposição de mudança social mais profunda, sintoma de uma ação político-cultural incompatível com a retórica liberal e às inovações demandadas pela própria ordem econômica.

O dilema social brasileiro caracteriza-se como um apego sociopático ao passado, que poderá ter conseqüências funestas. Ostenta-se uma adesão aparente ao progresso. Professa-se, porém, uma política de

\footnotetext{
${ }^{9}$ Os artigos foram publicados principalmente no jornal O Estado de S. Paulo, um dos principais divulgadores da campanha, material reunido em Educação e sociedade no Brasil (FERNANDES, 1966).
} 
conservantismo cultural sistemático. Os assuntos de importância vital para a coletividade são encarados e resolvidos à luz de critérios que possuíam eficácia no antigo regime, ou seja, há três quartos de século. Enquanto isso, as tensões se acumulam e os problemas se agravam, abrindo sombrias perspectivas para o futuro da nação. É patente que os adeptos dessa política estão cultivando, paradoxalmente, uma gigantesca revolução social, altamente sangrenta e destrutiva em sua fase de explosão. Qualquer que seja a posição que se tome, individualmente, diante de semelhante eventualidade, parece óbvio que se tornou crucial apontar aonde nos conduz, no momento, o ódio contra o radicalismo e a conseqüente paralisação de esforços nos âmbitos da reeducação dos homens, da renovação das instituições e da reconstrução da ordem social (FERNANDES, 1976, p. 212).

Novas considerações sobre outras dimensões do dilema social brasileiro estarão presentes também nas reflexões de Florestan sobre as questões étnico-raciais no Brasil, um conjunto de estudos sobre a "integração do negro" na nossa sociedade de classes (FERNANDES, 1965), que perfarão, articuladamente às suas preocupações com a nossa questão educacional, a base empírica de suas futuras investigações sobre os rumos da "revolução burguesa" num país capitalista "periférico" e "selvagem" (FERNANDES, 1975). Segundo Florestan, não é que por “aqui” a revolução deste tipo não tenha acontecido, ou, mesmo, que não possa acontecer. É que, ao fim e ao cabo, ela assume uma diversa consequência político-estrutural:

Mantidas as condições de dependência e de reduzido esforço para criar-se um padrão alternativo de desenvolvimento auto-sustentado, o capitalismo por aqui continuará a florescer como no passado remoto ou recente, socializando seus custos sociais e privilegiando os interesses privados (internos e externos) (FERNANDES, 1977, p. 178-179).

De acordo com Florestan, no nosso regime de classes, ficam bastante dificultadas as transições viáveis mesmo de "revoluções dentro da ordem", inclusive no campo educacional, tal como a ensaiada nos debates preparativos e definidores da nossa primeira LDB, entre os anos de 1948 e 1961. O próprio sociólogo será testemunha, em outros momentos da nossa história ${ }^{10}$, de que o dilema educacional brasileiro permanece funcionando como um círculo vicioso que acaba por sabotar os mínimos avanços instituídos por qualquer intervenção conjuntural deliberada, ainda que topicamente bem-sucedida.

\footnotetext{
10 Por exemplo, durante a reforma universitária efetivada, em 1968, pela Ditadura Militar (FERNANDES, 1979) e nos debates definidores de nossa última LDB, promulgada em 1996 (ADRIÃO; OLIVEIRA, 2001 e LEHER, 2012).
} 
Exige-se, nesses momentos, um esforço redobrado e repetido (dos interessados, é claro) para que não se coloque em cheque as conquistas das pequenas vantagens obtidas na ampliação das oportunidades educacionais das parcelas mais desassistidas da população nacional. Se isso não for feito, perde-se o pouco conquistado e abre-se terreno para a manutenção de uma perversa situação estrutural. Acabamos, assim, por registrar, nestes casos, meras aparências de mudança e inovação, que podem ser descritas como produtos estáticos da mobilidade social, urbana, industrial e educacional, que beiram, afirma Florestan, à imitação rarefeita dos modelos históricos originais.

Como não vão além disso, engendrando uma consciência e ações de classe negadoras da dependência, do subdesenvolvimento, dos privilégios, da opressão institucionalizada, do desemprego em massa e da miséria generalizada, elas se convertem em meios estruturais de perpetuação do capitalismo selvagem e de preservação do status quo (FERNANDES, 1977, p. 181).

\section{Considerações finais}

Esperamos ter demonstrado que na obra de Florestan Fernandes, articulado ao seu projeto sociológico de contribuição para o entendimento das questões nacionais, tem destaque à preocupação de compreensão da nossa questão educacional, que seria - nesta hipótese - um importante vetor de modernização das relações sociais. A Educação sistemática, segundo o sociólogo, deve ser considerada como um dos mais importantes instrumentos de difusão de uma consciência científica na sociedade. E, por consequência, um importante mecanismo político de mudança social planejada, tendo como base, entre outros fatores, uma efetiva relação dialógica entre educandos e educadores.

O foco central de nossa análise foi a gênese do conceito de "dilema educacional brasileiro", construído por Florestan durante sua participação nos debates que resultaram na nossa primeira Lei de Diretrizes e Bases (LDB), promulgada em 1961 - um dos mais relevantes capítulos da História da Educação brasileira, quando foi aberta a oportunidade de se organizar o sistema nacional de ensino. Nesta intensa discussão e disputa sobre os rumos educacionais do país, como lembra um dos seus principais interlocutores, o Brasil teve a oportunidade de conhecer "um novo Florestan": não mais apenas o pioneiro de uma nova forma de fazer sociologia por aqui, mas o publicista que demonstrou a relevância de 
que, em determinadas circunstâncias, o intelectual deve se lançar "a posições concretas de luta para melhorar as condições de vida de seu país" (CARDOSO, 1987, p. 25).

Em tempos de conflitos e disputas agudas no campo educacional, os partidários da educação pública como instrumento civilizatório podem tirar dessa experiência florestânica uma relevante lição: a importância da defesa da premissa anisiana de que, numa sociedade que se quer democrática, a oferta de uma Educação de qualidade não pode ser fonte de privilégio de nenhum contingente populacional específico (TEIXEIRA, 1957).

\section{Referências}

ADRIÃO, Theresa \& OLIVEIRA, Romualdo P. de (orgs.). Gestão, financiamento e direito à educação: análise da LDB e da Constituição Federal. São Paulo: Xamã, 2001.

BUFFA, Esther. Ideologias em conflito: escola pública e escola privada. São Paulo: Cortez/Autores Associados, 1979.

CARDOSO, Fernando Henrique. A paixão pelo saber. In: D'INCAO, Maria Angela (Org.). O saber militante: ensaios sobre Florestan Fernandes. Rio de Janeiro: Paz e Terra; São Paulo: UNESP, 1987.

COSTA, Cátia Couto da. (2004). Os empresários da educação e o sindicalismo patronal. Revista Brasileira de Educação, Rio de Janeiro: ANPED; Campinas: Autores Associados, no 26, p. 170-171, mai./ago. 2004.

FERNANDES, Florestan. Florestan Fernandes: Série Memória Viva da Educação Brasileira. Brasília: Ministério da Educação (MEC)/Instituto Nacional de Estudos e Pesquisas Educacionais Anísio Teixeira (INEP), 1991.
Universidade brasileira: reforma ou revolução? $2^{\mathrm{a}}$ ed. São Paulo: AlfaOmega, 1979.

- A sociologia no Brasil: contribuição par o estudo de sua formação e desenvolvimento. Petrópolis: Vozes, 1977.

- A sociologia numa era de revolução social. $2^{\mathrm{a}}$ ed. Rio de Janeiro: Zahar Editores, 1976.

- A revolução burguesa no Brasil: ensaio de interpretação sociológica. Rio de Janeiro: Zahar Editores, 1975. - Ensaios de sociologia geral e aplicada. $2^{a}$ ed. São Paulo: Pioneira, 1971. - Educação e sociedade no Brasil. São Paulo: Dominus/EDUSP, 1966.

sociedade de classes. São Paulo: Dominus/EDUSP, 1965. 2v. (Ciências Sociais Dominus, 3 ).

FERREIRA, Márcia dos Santos. O Centro Regional de Pesquisas Educacionais de São Paulo (1956/1961). 2001. 194f. 
Dissertação (Mestrado em Educação) Universidade de São Paulo, São Paulo.

FERREIRA, Marco Antônio Costa; OLIVEIRA, Newton de. Os Guardiães de Minerva. Rio de Janeiro: SINEPE/MRJ, 1997.

LEHER, Roberto. Florestan Fernandes e a defesa da educação pública. Educação $e$ Sociedade, Campinas, v. 33, n. 121, p. 11571173, dez. 2012. Disponível em: $<$ http://www.scielo.br/scielo.php?script =sci arttext\&pid=S0101-

$73302012000400013 \& \operatorname{lng}=$ en\&nrm $=$ iso

>. Acesso em: 15 mai. 2020.

NAGLE, Jorge. Um pensamento para a reconstrução. In: D'INCAO, Maria Angela (Org.). O saber militante: ensaios sobre Florestan Fernandes. Rio de Janeiro: Paz e Terra; São Paulo: UNESP, 1987.

NUNES, Clarice. Anísio Teixeira: a poesia da ação. Revista Brasileira de Educação, Rio de Janeiro: ANPED; Campinas: Autores Associados, no 16, p. 5-17, jan./abr. 2001.

OLIVEIRA, Marcos Marques de. Florestan Fernandes. Recife: Fundação Joaquim Nabuco, 2010.
ROMANELLI, Otaíza de Oliveira. História da educação no Brasil. 22a ed. Petrópolis: Vozes, 1999.

ROMÃO, Wagner de Melo. A experiência do Cesit: sociologia e política acadêmica nos anos 1960. 2003. 246f. Dissertação (Mestrado em Sociologia) - Universidade de São Paulo, São Paulo.

SAVIANI, Dermeval. Florestan e a educação. Estudos Avançados, São Paulo: Instituto de Estudos Avançados da USP, v. 10, no 26, p. 71-87, jan./abr. 1996.

SCHWARTZMAN, Simon; BOMENY, Helena. Maria Bousquet; COSTA, Vanda Maria Ribeiro. Tempos de Capanema. Rio de Janeiro, Paz e Terra; São Paulo, Edusp, 1984.

TEIXEIRA, Anísio. Educação não é privilégio. São Paulo: Cia. Editora Nacional, 1957.

XAVIER, Maria Elizabete Sampaio Prado. Capitalismo e escola no Brasil: a constituição do liberalismo em ideologia educacional e as reformas do ensino (1931-1969). Campinas: Papirus, 1990. 